\title{
Bioethanol Limbah Kulit Jeruk Manis (Citrus Sinensis L. Osbeck) Sebagai Peningkatan Nilai Oktan
}

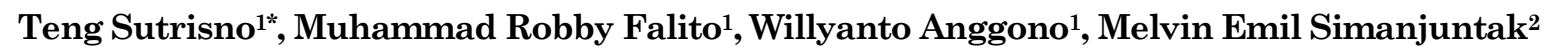 \\ ${ }^{1}$ Program Studi Teknik Mesin, Fakultas Teknologi Industri, Universitas Kristen Petra \\ Jl. Siwalankerto 121-131, Surabaya 60236, Indonesia \\ 2 Program Teknik Mesin, Politeknik Negeri Medan \\ Jl. Almamater 1, Padang Bulan, Medan 20155, Indonesia \\ * Penulis korespondensi; E-mail: tengsutrisno@petra.ac.id
}

\begin{abstract}
ABSTRAK
Bioetanol merupakan biofuel yang dapat mengantikan bahan bakar bensin. Selain itu bioetanol dihasilkan oleh proses fermentasi glukosa kemudian dilanjutkan dengan proses destilasi. Limbah kulit jeruk yang cenderung menjadi sampah organik yang tidak memiliki nilai ekonomis, mengandung kadar glukosa yang cukup tinggi. Oleh karena itu limbah kulit jeruk ini diprediksi dapat dijadikan bahan baku pembuatan bioetanol. Fermentasi dari limbah kulit jeruk ini dapat menghasilkan alkohol dengan kadar 94\%. Bioethanol ini digunakan sebagai pencampur bahan bakar bensin dengan RON 90 agar dapat meningkatkan kualitas bahan bakar. Pengujian karaketerisik bioethanol dilakukan dengan pengujian parameter gum konten, kandungan sulfur, distilasi volume penguapan, dan berat jenis. Kemudian campuran bensin dengan bioethanol dengan konfigurasi E20 (20 \% ethanol) dan E27 (27\% ethanol). Hasil pengujian dinamometer bahan bakar E20 menunjukkan peningkatan daya 2.90\% dan $3.18 \%$ dibandingkan dengan bahan bakar bensin 100\% RON 90 .
\end{abstract}

Kata kunci: Bioetanol, fermentasi, destilasi, energi terbarukan, kulit jeruk, peningkatan performa mesin.

\section{ABSTRACT}

Bioethanol is a biofuel that can replace gasoline. In addition, bioethanol is produced by the glucose fermentation process followed by the distillation process. Orange peel waste, which tends to become organic waste that has no economic value, contains high glucose levels. Therefore, this orange peel waste is used as raw material for making bioethanol. Fermentation of orange peel waste can produce alcohol with a content of $94 \%$. This bioethanol is used as a gasoline fuel mixer with RON 90 to improve the fuel's quality. Bioethanol characteristics are tested by the parameters of gum content, sulfur content, distillation evaporation volume, and specific gravity. Then a mixture of gasoline with bioethanol with a configuration of E20 (20\% ethanol) and E27 (27\% ethanol). The E20 fuel dynamometer test results showed an increase in power of $2.90 \%$ and $3.18 \%$ compared to $100 \%$ RON 90 gasoline.

Keywords: bioethanol, fermentation, distilisation, renewable energy, orange peel, increasing performance engine.

\section{PENDAHULUAN}

Keberadaan sampah di Indonesia menurut Wanda [1] mengalami penumpukan sampah B3 dari import negara eropa khususnya negeri Belanda. Hal ini merupakan bencana pencemaran lingkungan yang perlu ditindak pencegahannya. Negara harus memberika sanksi administrasi yang tegas dalam instrument hukum. Selain itu upaya pembuatan sistem pengelolahan sampah sangat ideal sebagai tanggung jawab bersama terhadap keberadaan sampah B3 telah beredar di negara Indonesia.
Rahayu dan Sukmono [2] menyatakn bahwa persentase Berat dan Volume Sampah pada Pasar Segiri Samarinda $88.28 \%$ merpakan sampah organik daun dan plastic berada pada 2,94\%. Dua makalah ini dinyatakan bahwa sampah B3 yang mencemari lingkungan cenderung akibat import dari negara maju dibandingakan oleh sampah dari pasar tradisional. Volume sampah pasar Segiri 1825,9 kg/hari diprediksi menghasilkan biogas sebesar 78,26\% dari kapasitas sampah organik daun. Dimana sampah organik daun terdiri dari sampah daun, buah-buahan, sisa makanan, tulang, sisik ikan dan sayuran. 
Sampah organik yang berpotensi menghasilkan bioenergy dapat berpotensi untuk mengurangi pengunaan bahan bakar fosil.

Bahan bakar fosil yang merupakan bahan bakar tidak dapat diperbarui, dapat dialihkan menggunakan bahan bakar terbarukan salah satunya bioenergi. Dimana bioenergi ini merupakan bahan bakar yang ramah terhadap lingkungan. Selain itu bahan bakar bioenergi dapat mengurangi terjadi pembakaran yang tidak sempurna, karena memiliki kadar oksigen yang tinggi. Salah satu bioenergi adalah bioethanol hasil fermentasi bahan bahan organik seperti sampah kulit jeruk. Fermentasi merupakan proses kimia yang melibatkan bakteri aerob untuk menghasilkan alkohol. Bioethanol $\left(\mathrm{C}_{2} \mathrm{H}_{5} \mathrm{OH}\right)$ berupa cairan bening tak berwarna, tidak beracun, mudah terurai dan tidak menghasilkan polusi. Bioethanol merupakan ethanol terbuat dari bahan organic yang mengandung glukosa yang tinggi. Glukosa merupakan bahan utama oleh tumbuhan untuk menyimpan kelebihan glukosa. Wiratmaja [3] menyatakan bioethanol dihasilkan oleh fermentasi berbagai tanaman-tanaman yang umum, seperti ketela, singkong, dan sampah-sampah organik lainnya.

Pengembangan dan pemanfaatan energi baru sebagai energy alternative dengan proses fermentasi limbah buah buahan salah satunya seperti limbah kulit jeruk manis (Citrus sinensis L. Osbeck) seperti pada gambar 1. Kulit jeruk manis merupakan salah satu limbah pertanian yang belum banyak imanfaatkan masyarakat. Salah satu kemungkinan pemanfaatannya adalah diubah menjadi sumber energi berupa organicol. Melalui proses hidrolisis, selulosa potensial diubah menjadi glukosa. Perubahan selulosa menjadi glukosa merupakan tahap yang strategis karena glukosa dibutuhkan untuk berbagai keperluan. Andini dkk [4] menyatakan bahwa glukosa dapat difermentasi lebih lanjut menjadi asam organik dan etanol. Maka dari itu berdasarkan hal tersebut, penelitian ini dilakukan dengan memanfaatkan limbah buah jeruk untuk dikonversi menjadi sumber energi alternatif, yaitu Bioetanol.

Metode yang dibutuhkan untuk merubah kulit jeruk menjadi bioetanol adalah menghaluskan menjadi bubur kemudian difermentasikan untuk menghasilkan alkohol. Hasil alkohol ini dimurnikan melalui proses distilasi secara berulang. Selanjutnya bioethanol ini dicampurkan dengan bahan bakar fosil. Tujuan dari penelitian ini adalah memanfaatkan limbah kulit jeruk manis untuk menjadikan bahan bakar bioethanol yang akan dicampurkan dengan bahan bakar minyak untuk meningkatkan RON pada bahan bakar.

Penelitian ini mengetahui karakterisik unjuk kerja sepeda motor terbaru saat ini tahun 2021 dengan rasio kompresi 1:11. Dimana menurut Kristanto [5] bahwa rasio kompresi mesin dengan 11: 1 mesin keluaran 2020 harus memiliki minimal bahan bakar dengan RON 92 keatas. Selanjutnya Ramirez dan Sanches [6] menjelaskan kualitas biomass yang dapat masuk dalam penjualan bahan bakar, bahwa sifat bahan bakar alternatif memiliki parameter unsur yang sama degan bahan bakar transportasi. Oleh karena itu itu biofuel tidak dapat langsung sebagai bahan bakar, melain sebagai bahan bakar campuran sehingga dapat meningkatkan nilai oktan dll. Biofuel untuk bahan bakar transportasi tidak terbatas dengan metode fermentasi seperti, Jonoadji dkk [7] telah melakukan hal yang sama namun dengan metode ektraksi. Proses ini menghasil bahan bakar alternatif untuk jenis campuran bahan bakar diesel. Oleh karena itu potensi sampah organik daun yang sangat besar khususnya sampah pasar berpotensi menjadi biofuel yang cukup besar.

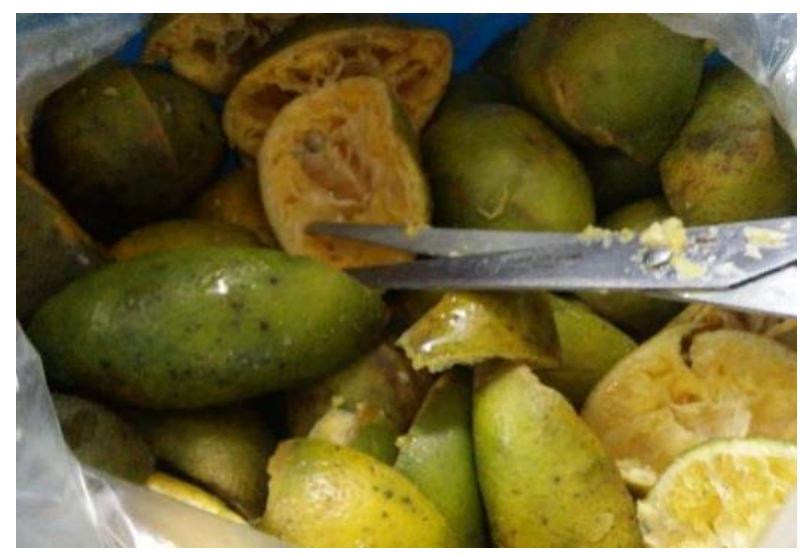

Gambar 1. Limbah Kulit Jeruk (Citrus sinensis L.Osbeck)

\section{METODE PENELITIAN}

Persiapan peralatan yang dibutuhkan dalam metode ini yaitu timbangan, gelas ukur, tabung distilasi dan botol penyimpan. Proses selanjutnya penghaluskan limbah kulit jeruk manis yang sudah di potong kecil-kecil dan mencampurkannya dengan takaran $4 \%$ ragi roti, 3\% pupuk urea dan air secukupnya memakai perbandingan 1:1 dengan masa kulit jeruk, lalu di haluskan menggunakan blender. Setelah itu limbah kulit jeruk yang sudah halus langsung segera melakukan proses fermentasi dengan variabel lama waktu fermentasi 5 hari dengan ketentuan semua parameter sama. Bila hasil dari fermentasi berbau pembusukan maka dapat di simpulkan hasil fermentasi telah gagal dan harus mengulangnya kembali dengan membedakan parameter ragi roti dan pupuk ureanya. Hasil dari fermentasi pengujian pertama kemudian didestilasi untuk mengetahui kadar alkholol dari limbah kulit jeruk. Setelah mendapat lama waktu fermentasi dan variable yang terbaik selanjutnya melakukan destilasi berulang. Proses distiliasi menggunakan dua jenis kondesor yaitu Liebug dan Graham. Kemudian dilanjutkan pada proses pengujian karakterisik bioethanol dengan kadar 94\% pada PT. Lemigas. Sedangkan pengujian dynamometer dilakukan pada 
Laboratorium Otomotif Universitas Kristen Petra. Standard dan prosedur pengujian sama dengan yang dilakukan oleh Sutrisno dkk [8]

\section{HASIL DAN PEMBAHASAN}

Pada penelitian ini dilakukan pencampuran bioetanol limbah kulit jeruk 94\% dengan bahan bakar RON 90 dengan persentase 20:80 E20 dan 27:73 E27 lalu melakukan pengujian karakteristik bahan bakar pada bioethanol E100 limbah kulit jeruk di lab PT.Lemigas, pengujian nilai HHV padaJurnal Mahasiswa Prodi Teknik Mesin Universitas Kristen Petra, Surabaya campuran E20, E27, dan G100 RON90, dan pengujian dinamometer menggunakan pencampuran bioetanol limbah kulit jeruk 94\% dengan bahan bakar RON 90 .

Perhitungan menggunakan rumus campuran. Pada campuran E20 dengan perbandingan 20\% bioethanol RON120 dan 80\% gasoline RON90 menghasilkan biofuel dengan RON96 seperti persamaan 1 , dan pada campuran E27 dengan perbandingan 27\% bioethanol RON120 dan 73\% gasoline RON90 menghasilkan biofuel dengan RON98.1 seperti persamaan 2.

$$
\begin{gathered}
O N_{B 20}=\text { Bioethanol }+ \text { Gasoline } \\
O N_{B 20}=\left(\%_{E 100}\right) O N_{E 100}+\left(\%_{G 100}\right) O N_{G 100} \\
O N_{B 20}=(20 \%) 120+(80 \%) 90 \\
O N_{B 20}=96 \\
O N_{B 20}=\text { Bioethanol }+ \text { Gasoline } \\
O N_{B 20}=\left(\%_{E 100}\right) O N_{E 100}+\left(\%_{G 100}\right) O N_{G 100} \\
O N_{B 20}=(27 \%) 120+(73 \%) 90 \\
O N_{B 20}=98.1
\end{gathered}
$$

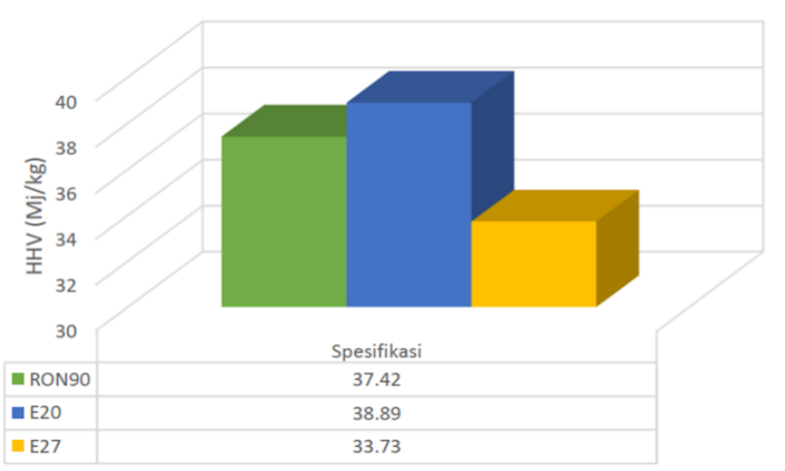

Gambar 2. Perbandingan nilai High Heating Value
Dari gambar 2 dapat dianalisa bahwa hasil nilai HHV pada campuran E20 memiliki angka HHV paling tinggi dengan nilai $\mathrm{HHV} 38.89 \mathrm{Mj} / \mathrm{Kg}$ yang kemudian disusul oleh nilai HHV dari bahan bakar RON90 sebesar $37.42 \mathrm{Mj} / \mathrm{Kg}$ dan yang memiliki nilai HHV paling rendah adalah E27 dengan nilai 33.73 $\mathrm{Mj} / \mathrm{Kg}$. Bahan bakar E27 memiliki nilai HHV rendah dikarenakan campuran E27 masih mengandung lebih banyak air sehingga sulit terjadi pembakaran dalam tabung bom kalorimeter.

Pengujian karakteristik bioetanol limbah kulit jeruk dilakukan di lab PT. Lemigas, dan lalu dibandingkan dengan data standart karakteristik bahan bakar. Data hasil pengujian dapat di lihat pada tabel 1 Berdasarkan hasil pengujian karakteristik bahan bakar dari parameter dengan perbandingan pengujian standart karakteristik bahan bakar dapat disimpulkan bahwa nilai hasil uji bioethanol tidak terlalu jauh dengan nilai standart karakteristik dari bahan bakar. nilai sulfur bioetanol juga lebih rendah dari pada standartnya yang mengartikan bahwa bioetanol ini sangatlah bersih.

Pengujian dinamometer dengan motor Honda CBR 150 cc dengan sistem injeksi dilakukan pada putaran mesin 4500 sampai dengan $1000 \mathrm{RPM}$ untuk mendapatkan nilai daya dan torsi aktual. Variasi bahan bakar berupa RON 90 100\%, E20 dan E27.

\begin{tabular}{|c|c|c|c|c|}
\hline \multirow{2}{*}{ Spesifikasi } & \multirow{2}{*}{ Metode Tes } & \multicolumn{3}{|c|}{ Nilai } \\
\hline & & Standard Gasoline & Gasoline RON 90 & Bioethanol E100 \\
\hline Sulfur (ppm), $\max$ & D 7039 & 80 & 50 & 7.1 \\
\hline $\begin{array}{l}\text { Distillation }\left({ }^{\circ} \mathrm{C}\right), \max 10 v \% \\
\text { recovered }\end{array}$ & & 55 & 74 & 69.5 \\
\hline $50 v \%$ recovered, $\min$ & D86 & 77 & 75 & 71 \\
\hline End point, $\left({ }^{\circ} \mathrm{C}\right), \max$ & & 225 & 215 & 98.5 \\
\hline Residue (v\%), $\max$ & & 2 & 2 & 2 \\
\hline $\begin{array}{l}\text { Solvent-washed gum content } \\
(\mathrm{mg} / 100 \mathrm{~mL}), \max \end{array}$ & D381 & 5 & 70 & 1.3 \\
\hline
\end{tabular}
Setiap pengujian dilakukan 5 pengambilan data.

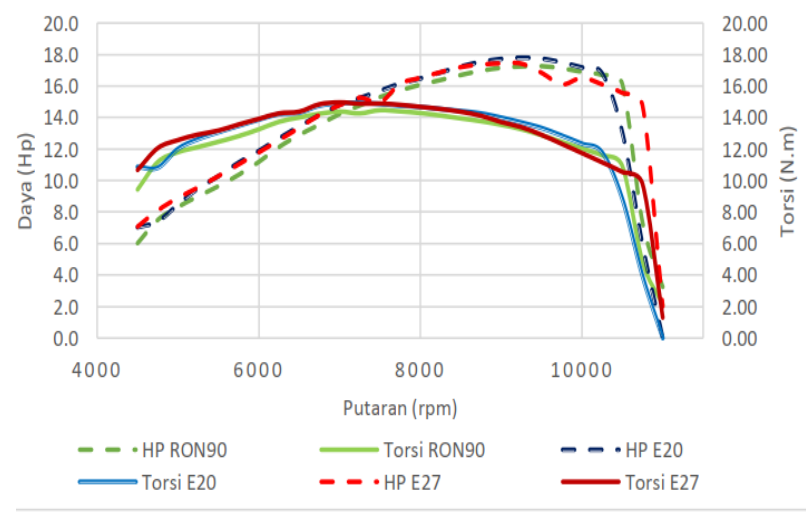

Gambar 3. Perbandingan Daya dan Torsi dengan penggunakan bahan bakar RON 90, E20 dan E27

Dari gambar 3 hasil dyno test terlihat bahwa titik tertinggi untuk daya G100 RON90 memiliki

Tabel 1. Hasil Pengujian Standard Gasoline, Gasoline RON 90 dan Bioetanal E100 
daya $17.3 \mathrm{hp}$ pada putaran $9500 \mathrm{rpm}$, untuk titik tertinggi daya pada bahan bakar E20 memiliki daya sebesar 17.8 hp pada putaran $9250 \mathrm{rpm}$, dan untuk titik tertinggi daya pada bahan bakar E27 memiliki daya sebesar $17.4 \mathrm{hp}$ pada putaran $9000 \mathrm{rpm}$. Sedangkan untuk torsi yang dihasilkan dari pengujian bahan bakar G100 RON90 memiliki torsi sebesar 14.47 N.m pada putaran 7500 rpm, untuk penggunaan bahan bakar campuran E20 memiliki torsi sebesar 14.93 N.m pada putara 7250 rpm, dan pada campuran E27 memiliki torsi sebesar 14.96 N.m pada putara $7000 \mathrm{rpm}$. Secara keseluruhan berdasarkan peningkatan putara dari pengujian dengan sampel E20 terjadi peningkatan hp pada kinerja mesin, sedangkan untuk sample E27 terjadi peningkatan pada torsinya, dibandingkan dengan bahan bakar RON90 campuran E20dan E27 lebih unggul dalam peningkatan daya dan torsi pada kinerja kendaraan Honda CB 150R.

\section{KESIMPULAN}

Dari Penelitian pemanfaatan bioetanol sampah kulit jeruk sebagai bahan campuran RON 90 dapat disimpulkan bahwa:

a) Terjadi peningkatan angka oktan pada campuran E20 dengan nilai oktan 96 dan campuran E27 dengan nilai oktan 98.1, peningkatan nilai oktan ini berpengaruh terhadap peningkatan unjuk kerja motor bensin.

b) Dari pengujian karakteristik bahan bakar sample E100 sebagian besar memenuhi syarat standard gasoline, yang dapat di artikan bahwa bioetanol dapat dicampurkan dengan gasoline.

c) Bahan bakar E27 lebih memiliki HHV yang lebih rendah dibandingkan campuran E20, memungkinkan campuran E27 memiliki kandungan air yang lebih dibandingkan campuran E20.

d) Pada pengujian dinamometer dengan menggunakan sepeda motor Honda CB 150R terjadi peningkatan kinerja mesin pada penggunaan bahan bakar E20 berupa daya $2.90 \%$ dan torsi sebanyak $3.18 \%$ dibandingkan dengan hasil daya dan torsi pada penggunaan bahan bakar RON90. e) Terjadi peningkatan brake mean effective pressure pada pengujian bahan bakar E20 sebesar $3.57 \%$ jika dibandingkan dengan brake mean effective pressure pada bahan bakar RON90.

\section{DAFTAR PUSTAKA}

[1]. Wanda, 2019, Upaya Indonesia Menanggulangi Limbah Sampah Plastik dari Belanda, JOM FISIP, 6(1), pp. 1-12.

[2]. Rahayu, D. E. dan Sukmono, Y., 2013, Kajian Potensi Pemanfaatan Sampah Organik Pasar berdasarkan Karakteristiknya, Jurnal Sains dan Teknologi, 5(2), pp. 77-90.

[3]. Wiratmaja, I. G., 2010, Pengujian Karakteristik Fisika Biogasoline Sebagai Bahan Bakar Alternatif Pengganti Bensin Murni, Jurnal Ilmiah Teknik Mesin Cakram, 4(2), pp. 145-154.

[4]. Andini, C., Mahajoeno, E., Setyaningsih, R., 2013, Production of Bioethanol from Citrus Fruit (Citrus sp) Waste by Acid Hydrolysis and Fermentation using Saccharomyces Cerevisiae, Proceeding Biology Education Conference, 10(2), pp. 1-6.

[5]. Kristanto, P., 2015, Motor Bakar Torak-Teori dan Aplikasinya, Andi Offset, Yogyakarta, Indonesia.

[6]. Ramirez, M. M. \& Sanchez, V., 2012, Challenges on the Quality of Biomass Deved Products for Bringing Them into the Fuels Market, Journal of Energy and Power Engineering, 6, pp. 321328.

[7]. Jonoadji, N., Sutrisno, Anggono, W., Sugondo A., Septhian, E, Simanjuntak, M. E., 2020, Pengaruh Penambahan Minyak Kulit Pisang terhadap Unjuk Kerja Mesin Diesel, Jurnal Teknik Mesin, 17(1), pp.17-22.

[8]. Sutrisno, T., Anggono, W., Lay, K., Simanjuntak, M. E., 2021, Optimasi Parameter Proses Pembuatan Bioetanol Sorgum Dan Pengaruh Terhadap Unjuk Kerja Motor Bensin, Otopro, 16(2), pp. 39-43. 